\title{
Computer Aided Legislation
}

Wojciech Cyrul

\section{Introduction}

The effective creation and accessing of legal texts in electronic format require the development and implementation of dedicated IT tools. These tools not only make possible the publication and accessing of the official texts of legal acts on the web, but also open up entirely new possibilities for the management of legislative processes and the information processed in them. The digitization of legal acts and other normative texts is also stimulating the development of public and private electronic legal information systems and highlights the importance of new technologies in the creation, accessing, retrieval and visualization of legal information.

The new possibilities offered by technological innovation in law-making have not only given rise to the phenomenon of e-legislation, but also laid the foundations for a new technical paradigm of thinking about the law - "Law as code"1. The widespread use of IT tools in the creation and accessing of law also means that more and more initiatives are being launched that highlight the new potential of the electronic text format in these areas. Examples include the automated consolidation of the texts of legal acts ${ }^{2}$, the automated translation of regulations ${ }^{3}$, and the development of systems that allow for the automation of legal information retrieval ${ }^{4}$,

1 Samer Hassan and Primavera De Filippi, 'The Expansion of Algorithmic Governance: From Code is Law to Law is Code' (2017) 17 Field Actions Science Reports.

2 Spinosa P. L., Giardiello G., Cherubini M., Marchi S., Venturi G., Montemagni S., 'NLP-based metadata extraction for legal text consolidation' (Proceedings of the 12th International Conference on Artificial Intelligence and Law, ACM, Barcelona 2009); Monica Palmirani, 'Legislative Change Management with Akoma-Ntoso' in G. Sartor and others (eds), Legislative XML for the Semantic Web. Principles, Models, Standards for Document Management (Springer 2011).

3 Atefeh Farzindar and Guy Lapalme, 'Machine Translation of Legal Information and Its Evaluation' in Nathalie Japkowicz and Yong Gao (eds) Advances in Artificial Intelligence (Springer 2009).

4 Jacek Petzel, Systemy wyszukiwania informacji prawnej (Wolters Kluwer 2017). 
the automation of legal references ${ }^{5}$ as well as new computer-aided methods for connecting and visualizing dispersed legal information ${ }^{6}$.

Understanding the evolution of law-making and law-sharing processes brought about by information technology (IT) requires interdisciplinary research. The use of IT in the processes of creating and accessing the law has led to multifaceted changes in the traditional practices of preparing, writing, storing and accessing legal texts, as well as in their retrieval, reading, interpretation and application. These changes require users to acquire and develop new skills as well as understand how new technologies work, including in particular in the ways in which they affect or can influence perceptions, assessments, preferences, choices, decisions and behaviours. Thus, the primary issue we are facing now is not so much the limits of the application of information technology in legislative practice, but rather the consequences of the implementation of new information tools in the creation and accessing of the law. Since a comprehensive analysis of such a wide-ranging problem goes far beyond the scope of this text, and the analysis below will focus solely on the role that IT plays in contemporary processes involving the drafting of legal texts in electronic format, the technical conditions regulating the computerization and algorithmization of legal texts as well as their on-line publication. It is on this basis that the concept of machine consumable legislation will be presented, assuming the incorporation of legal rules into the architecture of electronic systems with the aim of automating the activities described in the regulations ${ }^{7}$.

5 Franciszek Studnicki, Andrzej Łachwa, Jarosław Fall and Ewa Stabrawa, Odestania $w$ tekstach prawnych. Ku metodom ich zautomatyzowanej interpretacji (ZNUJ1990); Emil de Maat, Radbout Winkels and Tom van Engers, 'Automated Detection of Reference Structures in Law' in Tom M. van Engers (ed) Legal Knowledge and Information Systems (IOS Press 2006).

6 See also Wojciech Cyrul and Tomasz Pełech - Pilichowski 'Legislating in Hypertext', (2020) 118 OSAP 27; Janusz Opiła. and Tomasz Pełech-Pilichowski, 'Visual Analysis of Similarity and Relationships Between Legal Texts' (43rd International Convention on Information, Communication and Electronic Technology -MIPRO, 2020).

7 See also Matthew Waddington, 'Machine-consumable legislation: A legislative drafter's perspective - human v artificial intelligence' (2019) 2 The Loophole Journal of Commonwealth Assoc of Legislative Counsel. 


\section{The Role of Technology in the Darfting and Accesing of Legal Texts}

Although the first attempts to use computer systems when amending the law date back to the mid-twentieth century, information technology was initially limited to the task of remedying the legislative crisis caused by the steady increase in legal texts, such as acts and case law, that was beginning to overwhelm many Western countries. Since both an efficient state administration and economic growth depend on fast, cheap, easy and safe access to applicable laws, it is not surprising that despite initial teething problems, private and public systems of legal information began to emerge from the end of the 1960s onwards. The first public solutions of this type were two American systems - LITE (Legal Information Thru Electronics) and JURIS launched in 1972. The first European system of this type was the CREDOC (Center de documentation juridique), which was launched in September 1969 and made legal information available to every Belgian lawyer in all areas of law. Other initiatives from this period include the German JURIS system, ITALGIURE-FIND in Italy and Legifrance in France, which replaced the CENIJ (Center de recherches et développement en informatique juridique) service first launched in 1970. Providing access to legal information was also the motive behind the development of legal information systems in Poland. Work on the country's Central Register of Normative Acts (CRAN) began as early as 1974, and this system later provided the basis for the Internet System of Legal Acts, now available on the website of the Chancellery of the Sejm of the Republic of Poland.

To make printed legal texts available in electronic legal information systems, they first had to be scanned using OCR (Optical Character Recognition) technology. However, with the popularization of personal computers and the development of various computer applications, including word processors, electronic databases and related search systems, draft texts of legal acts begin to be prepared in electronic format.

The role of information technology in the creation and sharing of law was further enhanced with the advent of the Internet for general use. Thanks to the development and general availability of WWW architecture, users of computers operating in graphic mode (X-Windows, Apple McIntosh, MS Windows) gained simple access to all published web resources. What is more, thanks to the launch of search engines, they also acquired the ability to search web resources effectively without the need for advanced IT knowledge. This way, space was created for the development of public and commercial legal information services. However, it is important to bear in mind that even in the 1990s and at the beginning of the 21st century, the texts of legal acts were published in HTML as files in 
PDF or in other formats that only allowed them to be downloaded or viewed on the web. Only later were the texts of legal acts published in formats specially designed for legal documents, enabling not only advanced searches for such texts, but also the automation of their management and amendment. At the same time, from the very outset the specifications of digital formats were either tools developed by commercial companies or were created by public entities for their own needs, or were developed as an open standard, as was the case with Akoma Ntoso or LegalDocML.

The application of IT in the creation and accession of law has required the implementation of new solutions to ensure data security, both in terms of safeguarding the integrity of already published texts of legal acts as well as the texts of legal acts currently being drafted in the legislative process. Technical solutions are also largely entrusted with the task of ensuring the authenticity and accessibility of the texts of legal acts on the web. In particular, they are responsible for guaranteeing the integrity of legal texts, both at the database level and in their presentation, both at the legislative stage and when laws are published. IT solutions prevent, inter alia, alterations being made to the content of a document by unauthorized persons, errors occurring in the dating or versioning of individual documents, unauthorized changes to their format, inconsistencies between a presented and stored text, changes in semantic relations and changes in the syntax of the source file. ${ }^{8}$

When discussing the role of technology in the creation and accessing of the law, it is also important to note that ensuring data security required the use of different technical solutions in situations where the text of a legal act was made available in the form of a coherent, non-editable file in .Pdf format, available only for reading or download, and other solutions when the content of a legal act was generated on the basis of data selection and aggregation. In the first case, authenticity and security is ensured, on the one hand, by using the appropriate file format and software necessary to read it, and, on the other, by signing the document with a qualified electronic signature. In the latter case, providing data security is a much more complicated issue and depends to a large extent on the hardware and software infrastructure used. In both cases, however, the technological conditions for ensuring data transmission security must be taken into account. This requires not only the use of effective cryptographic solutions

8 Wojciech Cyrul, Jerzy Duda, Janusz Opiła and Tomasz Pełech- Pilichowski, Informatyzacja tekstu prawa. Perspektywy zastosowania języków znacznikowych, (Wolters Kluwer 2014). 
and key certification, but also the application of elementary security conditions for safe transmission, such as the use of packet filtration systems, intrusion detection systems and secure communication between resources, for example via dispersed database servers ${ }^{9}$.

\section{Computerization of the Texts of Legal Acts}

From the perspective of the legislative process, WWW architecture has contributed to a paradigm shift in the way law is published and accessed on a level similar to the digitization of legal information. The use of the Internet in the law-making process has resulted not only in the proliferation and diversification of our sources of knowledge of law on an unprecedented scale, but it has elevated the role of private and public legal information systems, such as ISAP, LEX and Legalis. Moreover, a number of tools have also been specially devised to support the work of legislators and facilitate the publication of legal texts on the Internet. Besides the above-mentioned editors legal acts, such as the Polish EDAP and EAP Legislator, the Italian xmLeges $^{10}$, the Dutch MetaVex ${ }^{11}$, or the American LegisPro, modern e-legislation systems, have also been developed which include not only editors supporting the preparation of the text of a legal act as well as services responsible for the electronic promulgation of approved legal acts, but also comprehensive systems managing all information flow (workflow) in the legislative process. One model example of such a solution is E-Recht, which was developed in Austria ${ }^{12}$.

Any analysis of the ongoing computerization of the law-making process must take into account the importance of public on-line consultation systems in draft legal acts. Such solutions have been successfully launched,

9 ibid 147.

10 Tommaso Agnoloni, Enrico Francesconi, Pierluigi Spinosa, 'xmLegesEditor: an OpenSource Visual XML Editor for supporting Legal National Standards' in Proceedings of the V Legislative XML Workshop (European Press Academic Publishing 2007).

11 Saskia van de Ven, Rinke Hoekstra, Radboud Winkels, Emile de Maat, and Ádám Kollár, 'MetaVex: Regulation Drafting meets the Semantic Web, in Pompeu Casanovas and others (eds) Computable Models of the Law (Springer 2008).

12 For more on this topic, see Brigitte Barotanyi, 'E-Recht: Law Making in a Contemporary Way' (2007) 1 Masaryk University Journal of Law and Technology 355. 
for example, in Greece, Lithuania, Luxembourg, Portugal and Hungary ${ }^{13}$. This shows that IT not only helps enhance the rationality and effectiveness of legal regulations, but also enables the creation of platforms promoting political debate and public consultations when issuing opinions on draft legal acts. Unfortunately, a planned Polish version of this type of system, initiated in 2012 by the now defunct Ministry of Economy, is currently not being supported by the Ministry of Development, Labour and Technology.

Despite the widespread use of IT in both the creation and application of the law, there is still insufficient knowledge among users with regard to how much the development, accessing and retrieval of reliable and relevant legal information depends on the application of specific standards for encoding and decoding information in a way that enables such information to be processed by machines. Failure to apply such standards may not only prevent access to information, but also affect its authenticity or integrity. Technical standards determine, among other things, the capability and methods of combining different information, as well as the ways used to describe the structure, content and displaying of individual documents. That is why it is so important that the standards used to create and access legal information are not only of a high quality but are also open in the broad sense of the term. This means, among other things, that they should be publicly accessible and understandable, as well as ensure the development and adaptation of such information to future needs. Moreover, their use should not be restricted by intellectual property rights ${ }^{14}$.

The establishment of uniform technical standards has resulted in the progressive standardization of the formats used for electronic documents containing legal information. This, in turn, has enabled in practice the automation of certain activities in the legislative process, e.g., automatic standardization of the texts of legal acts ${ }^{15}$. Thanks to these developments, it has also been possible to implement projects in the field of law based

13 High Level Group of Independent Stakeholders on Administrative Burdens, Europe can do better. Report on the best practice for implementing EU legislation in Member States in the least burdensome way (European Commission, 15 November 2011).

14 See. Fabio Vitali, 'A Standard-Based Approach for the Management for Legislative Documents' in Giovanni Sartor and others, (eds) Legislative XML for the Semantic Web. Principles, Models, Standards for Document (Springer 2011).

15 See also Wojciech Cyrul, 'Tekst jednolity aktu normatywnego $w$ formacie elektronicznym. W kierunku automatyzacji procesu ujednolicania tekstów prawnych' in Marzena Laskowska (ed) Znaczenie wyroków Trybunatu Konstytucyjnego dla tekstu jednolitego ustawy (Wydawnictwo Sejmowe 2017). 
on the idea of the semantic web. The latter term is usually understood as a heteronomous set of numerous formal statements about the content of the web and the world expressed in XML-based syntax and written using an ontology in a machine-readable format ${ }^{16}$.

The development of legislative systems based on the semantic web has been paralleled by attempts to promote the idea that legal information made available on the web should be processed not only at the level of individual characters in a text, but also after taking into account the structure of legal texts and the concepts contained therein. ${ }^{17}$. In other words, the purpose of the semantic web is to enable machines to process information contained in the texts of legal acts not only at the structural level, but also semantically, while maintaining determinism of action. ${ }^{18}$. Moreover, this concept is based on the assumption that any device or tool should be able to access the network, and, more importantly, that the quality of the solutions used should inspire users' trust. This means that these solutions should be safe and predictable in operation and should protect the privacy of the individuals who use them. Such an effect is possible thanks to the development and implementation of appropriate technological standards. Some of these already exist, while others are still in the preparatory or introductory stage. The first category includes, in particular, standards enabling the uniform representation of any graphic symbol based on alphanumeric codes, standards that ensure the unambiguous identification of objects available on the web, and standards that enable document structuring. Examples of the former include in particular: ASCII ISO / IEC 646, ISO 8859, EBCDIC, Windows-1250 and Unicode. Examples of the second are URI Uniform Resource Identifier), URL (Uniform Resource Locator) and IRI (Internationalized Resource Identifier), URN:Lex (Uniform

16 Joost Breuker, Pompeu Casanovas, Michel C.A. Klein, Enrico Francesconi, 'The Flood, the Channels and the Dykes: Managing Legal Information in a Globalized and Digital World' in Joost Breuker, Pompeu Casanovas, Michel C.A. Klein, Enrico Francesconi (eds), Law, Ontologies and the Semantic Web. Channeling the Legal Information Flood (Amsterdam 2009).

17 This is possible thanks to the use of markup languages such as XML, OWL or RDF. The XML language or its variants allows machines to recognize individual elements of a text's structure, and thus, for example, distinguish between a title and a paragraph or article, and languages such as OWL and RDF allow a machine to analyse a text in terms of its conceptual structure, and thus support or monitor the correctness of a user's actions.

18 The latter requirement significantly limits the use of fuzzy algorithms in the field of law, and it also imposes significant restrictions on systems using Artificial Intelligence $(\mathrm{AI})$ or Machine Learning $(\mathrm{ML})$ in this area. 
Resource Name:Lex), ECLI (European Case Law Identifier) as well as ELI (European Legislation Identifier.) Examples of standards make it possible to present the formal structure of legal texts in a way that allows for their automatic processing by machines, taking into account the meaning of statements about specific objects and their features, in particular XML, RDF, OWL, or standards specially designed for legal documents, such as, e.g., FORMEX, MetaLex, Akoma Ntoso, and LegalDocML. Standards ensuring the confidentiality, authenticity, integrity and certainty of information have also been developed and introduced. On the other hand, work is still underway on creating adequate legal ontologies, such as the LKIF, which would make it possible to provide a description of legal concepts and the relationships between them in a way that would allow machines to make complex inferences, take evidence and conduct conceptual analyses.

Bearing the above in mind, however, it should be remembered that the use of new IT tools to develop, process and publish legal texts in electronic form makes possible the automation not only of specific legislative activities, but also activities related to the provision, retrieval and application of legal information. At the same time, while the scope and possibilities of automation in this area were originally directly connected with the development of Knowledge Representation Languages (KRL) and efforts to find a way of representing legal information that is machine applicable, at the present time the majority of research has rejected this paradigm and focused instead on attempts to use Big Data and Machine Learning technologies for the purposes of creating and applying the law ${ }^{19}$. Although the new approach has great potential, it is worth recalling that it was KRLs, such as Lisp ${ }^{20}$, Smalltalk ${ }^{21}$, and above all Prolog ${ }^{22}$, that paved the way for legal knowledge to be represented in a form that allows machines to take into account the content of legal provisions. What is more, it is their limited usefulness in this area that was one of the factors behind the search for, and development of, new methods and architectures for inference systems capable of taking into account the semantic dimension of legal texts, such

19 Ződi Zsolt. 'Law and Legal Science in the Age of Big Data' (2017) 3 Intersections. EEJSP 69; Harry Surden, 'Machine Learning and Law' (2014) 89 Washington Law Review 87.

20 Jacek Martinek, Lisp - opis, realizacja $i$ zastosowania (Wydawnictwa NaukowoTechniczne1980).

21 Johannes Brauer, Programming Smalltalk - Object-Orientation from the Beginning, (Springer Vieweg 2015).

22 Robert A. Kowalski, 'Legislation as Logic Programs' in Zenon Bankowski and others (eds.), Informatics and the Foundations of Legal Reasoning (Springer 1995). 
as, for example, case-based reasoning, agent systems or network services. (SOA). The limitations of universal languages also meant that efforts were made to find alternative ways of writing legal knowledge. These steps, in turn, resulted in the development of dedicated solutions, such as the above-mentioned LKIF (Legal Knowledge Interchange Format), based on the OWL2 language and Argumentation Context Systems) ${ }^{23}$.

\section{Machine Consumable Legislation}

The idea of machine consumable legislation (MCL) is closely connected with the issue of using IT to increase legal certainty and effectiveness. Simply put, it comes down to the task of "incorporating" legal rules in digital reality. As a consequence, this strategy involves creating action space for individuals in such a way as to prevent behaviour inconsistent with certain rules. For obvious reasons, a similar approach is now quite common in business processes, where both the number, type, time and effects of activities performed by individuals can be strictly determined, controlled and supervised by a functioning information system. We can thus risk arguing that the above-presented approach is essentially based on the creative combination and transfer to the public sphere of two relatively well-known technical solutions, i.e., systems with progressive rules and markup languages that allow machines to recognize the structure and content of electronic documents. In the case of MCL, we are dealing not so much with new technology as with a new approach to creating and accessing law. It assumes the parallel preparation of draft texts of legal acts in natural language and software, which will operate in accordance with the provisions contained within them, which will be written in computer languages ${ }^{24}$. This approach thus postulates exploiting the enormous potential of publishing and accessing legislation in a contemporary electronic format, especially given the fact that nowadays legal acts are not only prepared with the use of text editors and saved in formats that allow them to be accessed online, but also as they are available in machine-readable formats.

23 Rinke Hoekstra, Joost Breuker, Marcello Di Bello, Alexander Boer 'LKIF Core: Principled Ontology Development for the Legal Domain' (2009) 188 Frontiers in Artificial Intelligence and Applications 21.

24 cf Waddington (n 8) 23 ff. 
In contrast to the semantic web, the MCL concept is not limited to the task of drafting legal texts in a machine-readable way, but also involves state authorities creating and sharing legally functioning software. The main purpose of such a solution is neither to enable users to find relevant legal information more easily, nor to automate the process of standardising the texts of legal acts, but rather to provide addressees of the law with software that will legally determine the consequences arising from specific circumstances specified in the law.

Despite appearances, the idea itself is not that revolutionary. In practice, public authorities currently use software for their internal needs, automating certain processes in accordance with legal requirements. Programmes of this type are used nowadays, for example, to calculate tax liabilities or pension rights ${ }^{25}$. The novelty of the discussed approach lies solely in the fact that the coded version of the law would be created by state authorities or at their request in parallel with the drafting of the text of a new legal act, and it would be publicly available to all interested entities, and not only to state offices and departments ${ }^{26}$.

There is no doubt that this approach has many advantages. Certainly, creating and ensuring access to a coded version of a legal act along with the text of the legal act will reduce the risk of errors that may arise in its absence, when the coming into force of a new law will require computer program developers to adapt to its requirements. Moreover, the availability of such a version would also make it possible to effectively test various solutions considered during the legislative process and to automatically check the consistency and completeness of a legal text. However, it remains an open question as to how and with what tools the coding process itself should function. Another important issue is to determine both the legal consequences of using such tools and their legal status. And although advocates of this approach also see it as an opportunity to introduce more "digitally friendly" legislation, it should not be forgotten that the broader application of this concept may require adapting the language of the law to the needs of computer systems. Moreover, given the political conditions shaping legislative processes, the expenditure incurred in creating coded versions of the texts of legal acts and the specific status of the law, there is little reason to believe that the above-discussed approach will become popular in the near future.

25 Giovanni Sartor, 'Legislative Information and the Web', in Giovanni Sartor and others (eds) Legislative XML for the Semantic Web (Springer 2011).

26 Cf Waddington (n 8) 26. 


\section{Conclusions}

The above reflections lead to the conclusion that changes in the traditional paradigm of creating and publishing the law have been accompanied by the increasing role of IT in the legislative process. The fact that most countries now produce and make accessible legal texts in electronic format is due to the fact that common national and international technical standards have been developed and implemented to make this possible. It is also important to aware that the quality and efficacy of creating and making accessible legal texts in an electronic format directly depends on the availability of appropriate tools supporting the work of legislators. Nowadays, it is difficult to imagine a modern legislative process without the existence of specially designed text editors for legal acts, converters, name servers, validators, e-legislation platforms, electronic consultation systems and many other tools facilitating the general management and publication of electronic documents.

The increasingly vital role that IT plays in the creation and application of the law is also a consequence of the common belief that it is an effective means of counteracting the crisis brought on by the spiralling number of legal texts. As a result, computerization is one of the main strategies for rationalizing and optimizing the legislative process. Contrary to, for example, deregulation, computerization cannot halt the phenomenon of legal inflation. On the contrary, it can be reasonably argued that it will further accelerate the accumulation of legal provisions. This is due to at least two factors. First of all, the growing importance and universality of IT has resulted in a need to regulate the principles of their creation and application. Secondly, this trend is altering the preferences of users who increasingly expect access to detailed, precisely formulated rules that ensure satisfactory regulation of strictly defined situations. Bearing in mind the fact that IT tools enable the fulfilment of these expectations, and at the same time allow lawmakers control over a constantly growing body of legal information, it should be assumed that their role in the legislative process will continue to expand. Although this fact may be a justified cause of alarm, it is important to recall that the IT tools currently available make possible the creation of platforms for promoting political debate and more productive public consultations when issuing opinions on draft legal acts. Moreover, electronic systems improve access to legal information, while at the same time guaranteeing its integrity and security. They also enhance the transparency, effectiveness and responsiveness of legislative processes, ensuring that a legal system can adapt rapidly and in a controlled fashion to changing social and economic conditions. In other words, in modern- 
Wojciech Cyrul

day countries IT has emerged as an important element in mechanisms safeguarding quality and legal certainty in practice. 